\begin{abstract}
АЛЕКСАНДР Цой
Лодзинский университет, Филологический факультет, Институт русистики, Кафедра языкознания (Лодзь, Польша)
\end{abstract}

\title{
Характеристика словарных статей в аспекте теории текста (на материале словарей служебных слов)
}

В лексикографии словарная статья признается основной единицей словаря и представляет собой текст особого рода. Эту особенность можно охарактеризовать как полифункциональность, которая заключается в том, что словарная статья выполняет много различных задач.

В основу типологии словарных текстов положена классификация Г. А. Золотовой, определяющая пять типов коммуникативных типов текста (регистров): репродуктивный, информативный, генеритивный, волюнтивный и реактивный. Конкретные текстовые реализации этих типов названы композитивами (Золотова 2001: 323). Словарная статья, согласно коммуникативной классификации Г. А. Золотовой, представляет собой репродуктивный композитив, и в ней, как репродуктивном композитиве (тексте), выделяют: 1) вокабулу (заголовочное слово); 2) дефиниционную часть; 3) иллюстративную часть. Дефиниционная и иллюстративная части разъясняют заголовочную единицу и описывающий ее основные характеристики и в них зафиксирован содержательный минимум слова.

Существующая тенденция создания лексикографических произведений, направленных на описание семантики служебного слова, в настоящее время реализована в различных словарях. В настоящее время имеется несколько типов описаний отдельных служебных слов или их групп в специальных словарях, словники которых содержат словарные статьи со служебными словами (см.: Бурцева 2005; Рогожникова 1983; Словарь структурных слов русского языка 1997; Ефремова 2001; Прияткина и др. 2001; Бурцева 2005). В совокупности перечисленные словари дают в разной степени полноты многоаспектную информацию о служебных словах - грамматическую, синтаксическую, семантическую, коммуникативную, прагматическую и просодическую - необходимую для правильного их понимания и использования в речи.

Эти словари в существующих лексикографических классификациях отнесены к словарям грамматическим (Шимчук 2003: 120-126 или Козырев, 
Черняк 2004: 144-147). Грамматические словари по классификации, предложенной Э. Г. Шимчук, содержат правила изменения слов, а также информацию, необходимую для построения высказываний и текстов, содержащих данное слово или данный ряд слов (Шимчук 2003: 119). В отличие от толковых словарей, также представляющих пользователю грамматическую информацию, грамматические словари содержат сведения о собственно морфологических и синтаксических свойствах кодифицируемого слова.

Целью статьи является анализ словарных статей на служебные слова с точки зрения текста.

Рассмотрим «Словарь наречий и служебных слов русского языка» В. В. Бурцевой (Бурцева 2005). В словарь, помимо наречий и служебных слов, включены как непроизводные, так и производные предлоги, союзы и частицы. междометия, вводные слова и словосочетания, предикативы, неизменяемые прилагательные. Задачей словаря является ознакомление пользователей с орфографией этих слов, помощь в различении наречий и предикативов, наречий и служебных слов. Как отмечает автор в предисловии, написание наречий и наречных сочетаний (словосочетаний и сочетаний существительных с предлогом, выступающих в роли наречий) запомнить невозможно, нужно непременно обращаться к словарю (Бурцева 2005: III). То есть, словарь в первую очередь орфографический, призван предоставлять пользователю информацию о правописании кодифицируемых лексических единиц.

Большое место в словаре уделено предикативам, в роли которых выступают краткие прилагательные и причастия (весел, красив, счастлив), наречия (нараспашку, обидно), существительные (безнадёга, гибель, конеи) и слова, выступающие в этой функции (жаль), которые сопровождаются пометой в знач. сказ. - в значении сказуемого. Включены в словарь вводные слова и словосочетания (например, к примеру, больще того, по счастью), неизменяемые прилагательные, обозначающие цвета (беж, индиго), а также устойчивые сочетания, выражающие различные пожелания, приветствия (доброе утро, добро пожаловать, как бы то ни было).

Структурно словарь построен по традиционному алфавитному принципу, леммы расположены в словнике словаря в алфавитном порядке. В случаях, когда лемма имеет варианты употребления, то они помещаются на своем алфавитном месте в виде отсылочных статей.

Составитель словаря все наречия и наречные сочетания и другие кодифицируемые единицы помещает в отдельных словарных статьях, расположенных по алфавиту. Известно, что и наречия и наречные сочетания, как и другие кодифицируемые единицы, в существующих толковых словарях помещаются в гнездо, внутрь, в содержание словарной статьи на производящее слово как дериваты. Кодифицируя в своем словаре наречия и наречные сочетания в отдельных словарных статьях, В. В. Бурцева дериваты наречия 
в отдельные словарные статьи не выделяет. Например, в одной словарной статье на наречие вон содержится лексикографическая информация на предикат, частицу и междометие:

Вон, разг. І. нареч. Наружу, за пределы чего-н., прочь. Быстро вынести вещи вон. Выйти вон. II. в знач. сказ. Удалить, удалиться, забыть, забыться. Из сердияа вон. Кто старое помянет, тому глаз вон. III. частица. 1. Указывает на происходящее или находящееся в отдалении. Вон он идёт. Вон там и остановимся. 2. Употребляется для усиления значения последующего слова или высказывания в целом. Вон ты какой вырос! Вон как ты стал говорить! IV. межд. Выражает приказ, требование немедленно уйти. Вон отсюда! Немедленно вон! (Бурцева 2005: 79). Или:

Вокру'г. І. нареч. Круго'м, в окружности, во все стороны. Вокруг всё было тихо. Вокруг расстилалась степь. Обойти дом вокруг. II. предлог c род. n. 1. кого-чего. Около, круго'м. Чего он ходит вокруг дома? Уселись вокруг стола. 2. кого-чего. По поводу кого-чего-н. Разговоры шли вокруг вчерашнего теракта. Вокруг неё всегда ходят сплетни (Бурцева 2005: 78). Или:

Хо'ть бы. І. союз. Выражает уступительность, даже если бы. Хоть бы решил пойти, всё равно не сможет. II. частица. 1. По меньшей мере, по крайней мере. Хоть бы цъветов купил что ли. 2. Выражает желательность, только бы, хорошо бы. Хоть бы помог (Бурцева 2005: 708).

Как видно из приведенных словарных статей составитель словаря в первую очередь преследовала цель представить в обозримом виде наречия и наречные сочетания, исключая последующие омонимы из списка полноценно кодифицируемых лексических единиц, приводя их в качестве компонентов словарной статьи, а не в отдельных самостоятельных словарных статьях.

После заголовочного слова при предлогах (а также при предикативах и наречиях) даются вопросительные слова, затем следует помета, относящая кодифицируемое слово к определенному грамматическому разряду, например:

Меж, кого-чего, кем-чем, предлог с род. и тв. пп.; устар. Между. Меж нами всё кончено. Меж высоких хлебов (Бурцева 2005: 259).

Вслед за этим следует стилистическая помета. Если она относится ко всем значениям кодифицируемого слова, то она помещается сразу после заголовочного слова:

Будь, частищз; разг. Говорится при прощании. Нy, будь, надеюсь, скоро встретимся (Бурцева 2005: 47).

Во-во', частица; прост. Выражает уверенное подтверждение слов собеседника. Во-во, так он и сказал (Бурцева 2005: 74).

Ибо, союз; книжн. Присоединяет придаточное предложение, выражая связь основания и следствия, потому что, так как. Не смог ему помочь, ибо не обладаю соответствуюшими способностями. Не желаю расставаться с вами, ибо люблю вас (Бурцева 2005: 188-189). 
Ка'к же, частица; разг. 1. Конечно, разумеется. Как же, неужели я могу тебе отказать. Приду обязательно, как же. 2. Выражает несогласие, отказ, насмешливое отрицание, как бы не так. Так я тебе и отдам эту книгу, как же. Как же, жди, мало ли что он обещал (Бурцева 2005: 213).

В случаях, когда стилистическая помета относится не ко всем значениям, она ставится после очередного индекса значения:

Если то'лько, частица. 1. Выражает условность, предположительность. Гулять завтра пойдём, если только дождя не будет. 2. разг. Выражает колебание, неуверенную готовность согласиться; неуверенное предположение о чём-н. как единственно возможном. Не хочу есть, если только чуточку. Куда же они пропали? Если только задержались у друзей (Бурцева 2005: 159-160).

Индексирование значений кодифицируемого слова производится при помощи римских и арабских цифр в зависимости от количества значений одного грамматического разряда. Каждое значение сопровождается примерами в виде самостоятельных предложений/речений, дополняющих и иллюстрирующих употребление леммы в речи:

Хоть. І. союз. 1. Присоединяет придаточные уступительные предложения, даже если, несмотря на то что. Всё равно придёт, хоть очень занят. 2. Присоединяет придаточное предложение с повелительным наклонением, указывая на безнадёжность положения, бессмысленность усилий. Хоть что хочешь говори, я тебе не поверю. Хоть весь свет обойди, другой такой жены не найдёшь. II. частица. 1. Усиливает слово, к которому относится, по крайней мере, пусть даже. Хоть немного отдохни. Хоть на время прекрати читать. 2. Указывает в качестве примера на то слово или словосочетание, к которому относится. Вот хоть наша с мужем жизнь, чем не пример. Возьми хоть своего сына, вот образеи для всех (Бурцева 2005: 707-708).

Через точку с запятой даются оттенки значений:

То'лько бы, частица. Выражает желательность, предпочтительность, возможность; при отрицании - с оттенком опасения. Только бы он взял трубку. Только бы его назначили нашим начальником. Только бы она не задержалась (Бурцева 2005: 654).

В качестве средства семантизации в словарных статьях используется также синонимическое толкование:

Благодаря' кому-чему, предлог с дат. n. Из-за кого-чего-н., по причине, вследствие чего-н. Благодаря дождю не так уж жарко. Благодаря тебе всё успел сделать (Бурцева 2005: 39).

Положительным в «Словаре наречий и служебных слов русского языка» является наличие стилистической зоны, которая последовательно и продуманно размещена в словарных статьях на служебные слова, подача после леммы вопросительных слов при предлогах. К недостаткам словаря следует отнести непоследовательность при выделении омонимов в отдельные 
словарные статьи, использование синонимического толкования служебных слов. С точки зрения теории текста словарные статьи в данном словаре соответствует определению минимального репродуктивного композитива.

Задача «Словаря эквивалентов слова: наречные, служебные, модальные единства» Р. П. Рогожниковой состоит в том, чтобы показать правильное использование данного служебного слова в определенной синтаксической конструкции, а также особенности построения синтаксических конструкций с данным служебным словом (Рогожникова 1991: 6). Словарь включает 1200 устойчивых сочетаний русского языка, эквивалентных слову, которые выполняют функции служебных и модальных слов, наречий, предикативов, местоимений и междометий. Словарь, на наш взгляд, ошибочно отнесен к словарям сочетаемости (Козырев, Черняк 2004: 154). Вслед за Э. Г. Шимчук полагаем, что этот словарь является грамматическим (Шимчук 2003: 122).

Целевой группой пользователей словаря являются инофоны, изучающие русский язык как иностранный и уже овладевшие основами русского языка. Как отмечает Р. П. Рогожникова в предисловии к своему словарю, эквивалентами слова она называет включенные в словарь устойчивые сочетания, которые равнозначны слову и характеризуются единым семантико-структурным целым, отличаются неизменной формой, единством значения. Функционально они соответствуют наречиям, предлогам, союзам, частицам, междометиям, вводным словам, но отличаются от них тем, что состоят из нескольких слов, знаменательных и служебных. Она справедливо считает, что подобные сочетания нельзя относить к фразеологическим единицам, поскольку они не обладают коннотацией, которая характерна для фразеологических единиц: поэтому эквиваленты слова не включаются в словари фразеологических единиц. В то же время такое сочетание «воспроизводится в речи как готовая единица и требует специального толкования и перевода» (Рогожникова 1991: 3).

Все эквиваленты в словаре располагаются в алфавитном порядке, ударение для данных сочетаний дается контекстуальное, в некоторых сочетаниях сохраняется на двух словах. Дополнительное ударение в заголовочном слове отмечается в факультативной транскрипции, когда она приводится. В случаях, когда ударение варьируется, варианты ударения указываются в заголовке словарной статьи.

В словаре, помимо эквивалентов слова, кодифицируются лексические единицы, которые названы автором аналогами эквивалентов. Под аналогами Р. П. Рогожникова подразумевает сочетания слов, которые в предложении выполняют функции определенных частей речи, но еще не подверглись полной грамматической абсорбции: в них еще не сформировалась «смысловая “идиоматичность” сочетания, проявляется лексическое значение знаменательного слова» (Рогожникова 1991: 6-7). Аналоги образуются на основе соединения служебного слова с полнозначным словом, имеющим абстрактное 
значение, в семантике которого содержится или может развиться элемент релятивности.

Аналоги наречий, предлогов, союзов, частиц и др. помечаются после заголовочного слова графическим маркером «светлый круг» - [О]. Например:

В ГЛУББ, О предлог с род. n. 1. Употр. при указании на что-л., внутрь, в середину, чего перемещается что-л. ... (Рогожникова 1991: 36).

Эквиваленты слова, выступающие в качестве двух или более разных частей речи, выделяются как омонимы в разных словарных статьях и индексируются арабскими цифрами справа вверху:

И ТО ${ }^{1}$, союз градац.-присоед., обычно со словами всего, только, лишь в первой части предложения ... (Рогожникова 1991: 106).

И ТО ${ }^{2}$, частица (разг.). 1. после того слова, к которому относится. Служит для усиления признака, действия ...(Рогожникова 1991: 107).

Функциональное значение эквивалента слова отделено от синонима графическим маркером «темный круг» - [•]. Иллюстрации употребления кодифицируемого слова представляют собой фразы, составленные на основе текстов из литературных произведений, а также цитаты из художественных произведений. Цитаты от фраз отделяются графическим маркером «белый квадрат» - [ $[$ ]. Синтаксические особенности употребления, не связанные с изменением грамматического или лексического значения (сочетаемость с какими-либо словами, употребление в новой синтаксической функции, в иной синтаксической позиции), отделяются от основного значения графическим маркером «вертикальная черта» - [ | ]. Свободные сочетания, омонимичные эквивалентам слова, приводятся в конце словарной статьи с указанием «не смешивать». Эта зона акцентирует внимание пользователя на особенностях употребления служебного слова. Использование перечисленных выше графических маркеров можно увидеть на примере слова несмотря на:

НЕСМОТРЯ' НА, предлог, с вин. п., с сущ., обозначающим действие, состояние лища, предмета. Употр. при выражении уступительных отношений. • Вопреки чему-л., независимо от чего-л. Несмотря на молодость, он был очень серьёзным. $\square$ Он нагнулся и увидел небольшого щенка, который, несмотря на все свои старания, никак не мог вылезть из воды. Тургенев. Муму. | с частицами и наречиями всё-таки, всё же, тем не менее $u \partial p$. Усилительно. Несмотря на тесноту в вагоне, всё же удалось встать у окна... (Рогожникова 1991: 163).

В случаях, когда кодифицируемое слово в сочетании с другими словами образует фразовое единство, такое употребление обозначается графическим маркером «тёмный квадрат» - [ $\mathbf{0}]$.

Например:

НАЧИНА' Я ОТ, предлог с род. $n$. То же, что начиная с (в 1 знач.). Я вспомнил Ростов Ярославский, ... когда мы стояли на звоннице под колоколами ...■ в сочетании с предлогам до или дееприч. кончая образует обо- 
собленный оборот при конкретизации местоим. весь ... (Рогожникова 1991: 152-153).

Продуманной и функционально полной является подача в словарной статье информации о варианте заголовочного слова: акцентном, фонематическом или морфологическом. Так, акцентные варианты, представленные в заголовочной зоне, отделяются друг от друга маркером «точка с запятой» [; ], например:

ЕЩЁ PA'3; ЕЩ̈̈' РА3, О наречие. Снова, опять. Ещё раз благодарю вас за помощь./ Завтра мы с вами встретимся ещё раз. $\square$ В небе ещё раз громыхнуло, но теперь уже тише, умиротвореннее. Евтушенко. Ягодные места ... (Рогожникова 1991: 100).

Фонематические варианты, связанные с редукцией одного из компонентов или, наоборот, с более полным произношением (написанием) компонента сочетания, а также морфологические варианты (варианты суффиксов, падежных окончаний, употребления форм единственного и множественного числа, особенностей согласования в роде) - представлены в круглых скобках (Рогожникова 1991: 10):

ВСЁ ЖЕ (Ж), частища. 1. Служит для усиления противопоставления чему-л., ранее высказанному ... (Рогожникова 1991: 71).

НА ПУТИ' (ПУТЯ'Х), О предлог с род. $n$. (книж.) с отвлеч. сущ. Употр. при указании на какой-л. процесс, развитие, какую-л. деятельность ... (Рогожникова 1991: 145).

Р. П. Рогожникова в структуре словарной статьи выделяет, используя графический маркер «угловые скобки» - [<>; ২], факультативные словесные или пунктуационные элементы, которые употребляются в зависимости от смысла, интонации или логического выделения в предложении. Например:

А КА'К ЖЕ; НУ‘, А КА'К ЖЕ, частица (разг.) в ответной реплике. Служит для подтверждения сказанного, подчеркивает категоричность утверждения ... (Рогожникова 1991: 19).

В РАСЧЁТЕ < НА ТО'>, ЧТО, О союз. причин. Присоединяет придаточную часть предложения, в которой содержится предполагаемая причина действия в главной части ... (Рогожникова 1991: 66).

Большинство эквивалентов слова сопровождаются стилистической пометой, которая заключена в круглые скобки. В отличие от традиционного графического маркера «тёмный ромб» - [^], указывающего на наличие в словарной статье фразеологической единицы, в словаре используется маркер «тёмный треугольник» - $[\mathbf{A}]$ :

ХО’ТЬ БЫ, частица (разг.). 1. Выражает пожелание, надежду на что-л. • Хорошо бы, пусть бы. Солнце жжет мне лицо и руки. Накрыться нечем. Хоть бы ночь поскорее. Гаршин. Четыре дня ...

А Хоть бы хны' (прост.). То же что хоть бы что. - Загордился, право! сказал Лука, подбегая. - Кричу, кричу, он хоть бы хныл! В. Беляев. Старая крепость ... (Рогожникова 1991: 229-230). 
Как видно из словарной статьи, в ней выделяются следующие структурные зоны: лемма, зона просодии, зона стилистических помет, зона грамматической информации, зона значения, зона толкования, зона иллюстрации, зона оттенков значения, зона идиоматики.

Словарь можно охарактеризовать как полноценное лингвоцентрическое произведение лексикографического жанра с продуманной системой помет, с детальной лингвистической и лексикографической проработкой всех вариантов и факультативных элементов кодифицируемого слова, теоретически обоснованным выделением в лексической системе русского языка аналогов служебных слов и их последующей кодификацией в словаре. Недостатком словаря является отсутствие в нем словарных статей на непроизводные (первичные) служебные слова. С точки зрения теории текста словарные статьи в данном словаре следует определить как развернутый репродуктивный композитив.

Наиболее значимые характеристики словарей, содержащих словарные статьи на служебные слова, приведены в следующей таблице.

Таблица

Сравнительная характеристика словарей различных типов, содержащих в своей структуре словарные статьи на служебные слова

\begin{tabular}{|c|c|c|c|c|}
\hline № & $\begin{array}{c}\text { Наименование } \\
\text { словаря }\end{array}$ & $\begin{array}{c}\text { Тип } \\
\text { словаря }\end{array}$ & $\begin{array}{c}\text { Кодифициру- } \\
\text { емые лекси- } \\
\text { ческие еди- } \\
\text { ницы }\end{array}$ & $\begin{array}{c}\text { Зоны } \\
\text { лексикографиро- } \\
\text { вания }\end{array}$ \\
\hline & 1 & 2 & 3 & 4 \\
\hline 1 & $\begin{array}{l}\text { Бурцева В. В. Словарь } \\
\text { наречий и служебных } \\
\text { слов русского языка. } \\
\text { - М.: Рус. яз. - Медиа, } \\
\text { 2005. - VIII, 750, [10] } \\
\text { с. }\end{array}$ & $\begin{array}{l}\text { орфогра- } \\
\text { фиче-- } \\
\text { ский }\end{array}$ & $\begin{array}{l}\text { наречия, } \\
\text { предлоги, } \\
\text { союзы, } \\
\text { частицы, } \\
\text { междометия, } \\
\text { вводные слова } \\
\text { и словосоче- } \\
\text { тания, } \\
\text { предикативы, } \\
\text { неизменяемые } \\
\text { прилагатель- } \\
\text { ные }\end{array}$ & $\begin{array}{l}\text { лемма, } \\
\text { зона грамматиче- } \\
\text { ской информации, } \\
\text { зона стилистиче- } \\
\text { ских помет, } \\
\text { зона значения, } \\
\text { зона толкования, } \\
\text { зона иллюстрации }\end{array}$ \\
\hline
\end{tabular}




\begin{tabular}{|c|c|c|c|c|}
\hline & 1 & 2 & 3 & 4 \\
\hline 2 & $\begin{array}{l}\text { Рогожникова Р. П. } \\
\text { Словарь эквивалентов } \\
\text { слова. Наречные, слу- } \\
\text { жебные, модальные } \\
\text { единства. - М.: Рус. } \\
\text { яз., 1991. - } 254 \text { [1] с. }\end{array}$ & учебный & $\begin{array}{l}\text { предлоги, } \\
\text { союзы, } \\
\text { частицы, } \\
\text { междометия, } \\
\text { наречия, } \\
\text { предикативы, } \\
\text { местоимения }\end{array}$ & $\begin{array}{l}\text { лемма, } \\
\text { зона просодии, } \\
\text { зона грамматиче- } \\
\text { ской информации, } \\
\text { зона стилистиче- } \\
\text { ских помет, } \\
\text { зона значения, } \\
\text { зона толкования, } \\
\text { зона иллюстрации, } \\
\text { зона оттенков зна- } \\
\text { чения, } \\
\text { зона идиоматики }\end{array}$ \\
\hline
\end{tabular}

Проанализированные обзорно словари разных типов взаимно дополняют друг друга, описывая в лексикографическом формате различные аспекты функционирования системы служебных слов. Они составлены на основе использования принципа минимизации лексического состава русского языка, являются системно-ориентированными, неравномерно отражают лексикосемантическую структуру служебных слов русского языка. В толкованиях значений служебных слов словари предоставляют пользователю минимум семантических сведений, который необходим для идентификации релятивного понятия в семантическом континууме, но не способен обеспечить языковую коммуникацию. С точки зрения теории текста словарные статьи в проанализированных словарях следует определить как репродуктивные композитивы с различной степенью полноты.

\section{Библиография}

Бурцева В. В. Словарь наречий и служебных слов русского языка, Москва.

Ефремова Т. Ф. (2001), Толковый словарь служебных частей речи русского языка, Москва.

Золотова Г. А. (2001), К вопросу о структуре текстов разного коммуникативного назначения,

[в:] Языковая система и ее развитие во времени и пространстве: Сб. научн. ст. к 80-летию проф. К. В. Горшковой, Изд-во МГУ, Москва, с. 322-328.

Козырев В. А., Черняк В. Д. (2004), Русская лексикография: Пособие для вузов, Москва.

Прияткина А. Ф., Стародумова Е. А., Сергеева Г. Н. и др. (2001), Словарь служебных слов русского языка, Владивосток.

Рогожникова Р. П. (1991), Словарь эквивалентов слова. Наречные, служебные, модальные единства, Москва.

Морковкин В. В., Луцкая Н. М., Богачева Г. Ф. и др. (1997), Словарь структурных слов русского языка, Москва.

Шимчук Э. Г. (2003), Русская лексикография: Учебное пособие, Москва. 


\title{
Alexandr Tsoy \\ Characteristics of Dictionary Entries According to Theory of Text (On the content of dictionaries of connective words)
}

\begin{abstract}
Summary
The objective of the article is to analyze dictionary entries on connective words from the viewpoint of a text. A dictionary entry, according to the communicative classification of G. A. Zolotova, is a reproductive com-positive*.

On the basis of this, the dictionary entries in the «Dictionary of Adverbs and Connective words of the Russian Language» correspond to the definition of a minimal reproductive com-positive, and the dictionary entries in the «Dictionary of Word Equivalents: Adverbial, Syncategorematic, Modal Unities» should be defined as an extensive reproductive com-positive.
\end{abstract}

